\title{
Acute sensory ataxic neuropathy
}

INSERM

\section{Source}

INSERM. (1999). Orphanet: an online rare disease and orphan drug data base. Acute sensory ataxic neuropathy. ORPHA:231466

Acute sensory ataxic neuropathy is a rare variant of Guillain-Barré syndrome characterized by acute onset monophasic sensory neuropathy with diminished or absent tendon reflexes, loss of proprioception, positive Romberg sign and nerve conduction features of demyelination. It presents several weeks after acute infection with paresthesias, ataxia and neuropathic pain. 